\title{
Herpesvírus bovino tipo 1: Tópicos sobre a infecção e métodos de diagnóstico'1
}

\author{
Bovine herpervirus type 1: infection and diagnosis methods ${ }^{1}$
}

\author{
Elisabete Takiuchi²; Alice Fernandes Alfieri3; Amauri Alcindo Alfieri ${ }^{3}$
}

\begin{abstract}
Resumo: O herpesvírus bovino tipo 1 (BHV-1) encontra-se amplamente disseminado em rebanhos de corte e leite, determinando grandes prejuízos econômicos à exploração pecuária. A infecção pelo BHV-1 pode comprometer os tratos respiratório, genital, reprodutivo e nervoso e ocasionar uma ampla variedade de manifestações clínicas que são comuns a outras doenças infecto-parasitárias, inviabilizando o diagnóstico clínico conclusivo. Várias metodologias foram desenvolvidas para a realização do diagnóstico laboratorial do BHV-1. Contudo, as técnicas sorológicas tradicionais são incapazes de diferenciar a soroconversão originada pela infecção natural daquela devido à vacinação. Com isto, o diagnóstico conclusivo somente é possível pela identificação do BHV-1 diretamente em amostras clínicas. O isolamento viral em cultivo celular apresenta como desvantagem a necessidade da viabilidade da partícula viral, o que em muitas situações pode ocasionar uma redução na sensibilidade e especificidade da técnica. As técnicas de imunoperoxidase e imunofluorescência, apesar de não exigirem a infecciosidade do vírus, podem ser seriamente comprometidas caso a integridade estrutural da partícula não seja mantida. Atualmente a técnica da reação em cadeia pela polimerase está sendo universalmente adotada no diagnóstico de diversas viroses, inclusive do BHV-1. Esta metodologia apresenta como principais vantagens a não exigência da viabilidade da partícula viral, alta sensibilidade / especificidade e rapidez na obtenção dos resultados.
\end{abstract}

Palavras-chave: bovino, herpesvírus bovino tipo 1, rinotraqueíte infecciosa bovina, diagnóstico, PCR.

\begin{abstract}
Bovine herpervirus type 1 (BHV-1) is widespread in beef and dairy herds, causing great economic losses in cattle breeding. Infections caused by BHV-1 involving the respiratory, genital, reproductive and nervous systems can determine a wide variety of clinical manifestations wich are common on the other infectious and parasitic diseases. Several methodologies have been developed for laboratory diagnosis of BHV-1. Traditional serological techniques are unable to diferentiate animals exposed to the virus strains in the vaccine from those seropositives by natural exposure to the field strains. Thus the diagnosis can only be conclusive by detecting BHV-1 directly in clinical samples. Virus isolation has the disadvantage of requering viability in the viral particle, which in many situations may reduce the sensitivity and specificity of the technique. The immunoperoxidase and immunofluorescent techniques, although they do not require the infectiousness of the virus, can be seriously compromised if the structural integrity of the viral particle is not maintained. Currently the polymerase chain reaction assay is being universally adopted in the diagnosis of many virus, including BHV-1. This methodology has the advantage of not requiring the viral particle viability while providing high sensitivity and specificity and fast results.
\end{abstract}

Key words: Bovine, bovine herpesvirus type 1, Infectious bovine rhinotracheitis, diagnosis, PCR.

\section{Etiologia}

O herpesvírus bovino tipo 1 (BHV-1) encontra-se amplamente disseminado, determinando grandes prejuízos econômicos aos países que exploram a bovinocultura como atividade econômica (KIRKBRIDE, 1985).

O BHV-1 pertence à família Herpesviridae, sub-família Alphaherpesvirinae. A partícula viral tem entre 70 a 110 nm de diâmetro e é constituída por um capsídeo icosaédrico, envelope glicoproteico e genoma DNA linear de fita dupla (FENNER, 1987).

O envelope viral é composto por dez glicoproteínas, denominadas gB, gC, gD, gE, gl, gH, gL, gG, gK e gM. As glicoproteínas do BHV-1 diferenciam-se em suas propriedades antigênicas, moleculares e função biológica nos processos de interação com a célula hospedeira e de replicação (SCHWYZER; ACKERMANN, 1996).

Três glicoproteínas do envelope, devido a sua localização e função biológica, possuem grande potencial imunogênico. A gB é a mais imunogênica e, durante a replicação viral, está envolvida nas etapas de adsorção, penetração e fusão celular (VAN DRUNEN LITTEL - VAN DER HURK et al., 1990). A gC é muito importante na indução de anticorpos neutralizantes, sendo-lhe atribuída a função de adsorção do vírus à célula hospedeira (OKAZAKI et al., 1987). A gD é uma glicoproteína essencial para a replicação viral e sugere-se que também esteja envolvida na adsorção, penetração e fusão celular (FEHLER et al., 1992).

\footnotetext{
${ }^{1}$ Apoio Financeiro: CNPq, CAPES e CPG/UEL

${ }^{2}$ Aluna do Programa de Pós-graduação (nível: Mestrado) em Sanidade Animal / UEL

${ }^{3}$ Laboratório de Virologia Animal, Departamento de Medicina Veterinária Preventiva, Centro de Ciências Agrárias, Universidade Estadual de Londrina.e-mail: <alfieri@uel.br>
} 
Outra proteína constituinte do BHV-1 é a timidina kinase. Embora esta enzima não seja de fundamental importância para a replicação do vírus em cultivo celular, atribui-se a ela o envolvimento no processo de reativação do BHV-1 em estado de latência (SCHWYZER; ACKERMANN, 1996).

\section{Sinais Clínicos}

A infecção determinada pelo BHV-1 afeta principalmente os tratos respiratório e genital dos bovinos e pode ser subdividida em duas entidades clínicas denominadas Rinotraqueíte Infecciosa Bovina (IBR) e Vulvovaginite/ Balanopostite Pustular Infecciosa (IPV/IPB) (GIBBS; RWEYEMANN, 1977).

A forma respiratória caracteriza-se por aumento da temperatura corporal, hiperemia das mucosas, rinite, dispnéia, corrimento nasal seroso, lesões erosivas na mucosa nasal e, ocasionalmente, pneumonia. A taxa de mortalidade é baixa mas podem ocorrer complicações em decorrência de infecções bacterianas secundárias ou de outras infecções virais superpostas (KAHRS, 1977; WYLER et al., 1989).

Em fêmeas, a forma genital manifesta-se clinicamente pelo aparecimento de pequenas vesículas de 1 a $2 \mathrm{~mm}$ de diâmetro que evoluem para pústulas e erosões localizadas na vulva e vagina. O epitélio vulvar apresenta-se edemaciado, hiperêmico e com secreção que pode tornar-se mucopurulenta devido à contaminação bacteriana secundária. Em touros, lesões similares são encontradas no prepúcio e pênis (GIBBS; RWEYEMANN, 1977; WYLER et al., 1989).

Entretanto, IBR e IPV não são as únicas formas de manifestação clínica das infecções pelo BHV-1. Tanto em rebanhos de corte quanto de leite também podem ocorrer quadros clínicos de conjuntivite, enterite, encefalite e distúrbios reprodutivos. Estes são caracterizados por mortalidade embrionária precoce e/ou tardia, com repetições de cios a intervalos regulares e/ou irregulares; mortalidade fetal com aborto; natimortos; mortalidade neonatal e infertilidade (KARHS, 1977; STRAUB, 1991).

O BHV-1 pode ser classificado em sub-tipos, sendo o BHV-1.1 (IBR-like) relacionado com problemas respiratórios, reprodutivos e casos de conjuntivite. $\mathrm{O} \mathrm{BHV}$ $1.2_{A}$ e BHV-1.2 (IPV-like) são mais freqüentes em infecções relacionadas com o trato genital. O BHV-1.3 e o BHV-1.3 $3_{B}$, atualmente reclassificados como BHV-5, determina sintomatologia nervosa em bezerros e animais adultos sendo responsável pelo quadro clínico de meningoencefalite (PAULI et al., 1981; ROEHE et al., 1997).

\section{Transmissão}

A transmissão do BHV-1 pode ocorrer por inalação de aerossóis contaminados ou por contato direto com secreções nasais de animais infectados. Ambas as formas de transmissão são consideradas importantes na disseminação do vírus em rebanhos criados sob condições confinadas (VAN DONKERSGOED; BABIUK,
1991). A transmissão indireta ocorre principalmente pela ingestão de água e alimentos contaminados e pelo uso, nas coletas de sêmen, de vaginas artificiais contaminadas (ENGELS; ACKERMANN, 1996).

Outra forma de transmissão é a venérea, pela monta natural e/ou inseminação artificial (IA) onde, nesta última, o sêmen desempenha papel fundamental na cadeia epidemiológica (PHILPOTT, 1993). O sêmen geralmente é contaminado durante a ejaculação, por contato com o vírus presente na mucosa prepucial. Vários estudos demonstram que muitos patógenos presentes no sêmen podem manter-se viáveis frente ao processo de congelamento, tornando a prática da IA uma possível veiculadora de doenças no rebanho (EAGLESOME; GARCIA, 1992). A IA de vacas com sêmen contaminado pelo BHV-1 reduz a taxa de concepção e pode causar infertilidade, endometrite, aborto e o desenvolvimento anormal do feto (ELAZHARY et al., 1980; WYLER et al., 1989).

Uma das principais conseqüências resultantes da primo-infecção pelo BHV-1 é a capacidade do vírus permanecer em estado de latência, mantendo-se em gânglios periféricos sem se replicar e persistindo por toda a vida do animal (ACKERMANN; WYLER, 1984). Este mecanismo justifica os períodos de reexcreção viral, acompanhados ou não de sinais clínicos, de forma que os animais uma vez infectados pelo BHV-1 serão portadores do vírus e potenciais disseminadores da doença no rebanho por toda a vida produtiva (STRAUB, 1990). O mecanismo de indução da latência viral ainda não é totalmente conhecido, porém sabe-se que durante a reativação o BHV-1 é transportado via nervosa, a partir dos gânglios periféricos, retornando ao foco primário da infecção. Neste local ocorre replicação e eliminação viral. Casos de reativação do BHV-1 foram observados em animais submetidos ao tratamento com corticosteróides ou a condições variadas de estresse (DENNET et al., 1976). Durante o período de latência não são sintetizadas proteínas virais. Conseqüentemente, devido a não apresentação de antígenos do BHV-1 ao sistema imunológico, pode ocorrer decréscimo no título de anticorpos neutralizantes (ACKERMANN et al., 1982).

A introdução do BHV-1 em rebanhos bovinos determina prejuízos econômicos significativos que são representados por alterações em todos os índices indicativos de eficiência reprodutiva do rebanho. São particularmente comprometidos: i) intervalo entre-partos; ii) número de doses de sêmen e/ou número de serviços por prenhez positiva; iii) taxa de concepção; iv) taxa de mortalidade embrionária precoce e/ou tardia; v) percentagem de abortos, natimortos e mortalidade neonatal; vi) peso ao nascer; vii) freqüência de endometrites; entre outros. Também devem ser incluídos em uma análise dos prejuízos econômicos decorrentes da infecção em um rebanho soronegativo os custos referentes à redução na produção de leite; perda de peso; tratamento dos animais com sinais clínicos, em especial os que comprometem o sistema respiratório; eventuais óbitos; além do aumento das despesas com mão de obra, assistência técnica, diagnóstico e profilaxia (WYLER et al., 1989). 


\section{Epidemiologia}

O BHV-1 está presente em rebanhos bovinos de praticamente todo o mundo (GIBBS; RWEYEMANN, 1977). Na maioria dos países europeus, a situação é endêmica e as taxas de infecção descritas são muito variáveis. Na Grã-Bretanha o percentual de rebanhos soropositivos alcança 40 a $50 \%$ e na Bélgica, $62 \%$. Por outro lado, Dinamarca e Suíça, devido à baixa freqüência de animais soropositivos e a implementação de um rígido programa de erradicação, com o sacrifício dos animais portadores, conseguiram obter a condição de países livres do BHV-1 (ACKERMANN et al., 1990). Na América do Norte a infecção apresenta caráter endêmico sendo que os sinais clínicos são controlados por meio de programas de vacinação. No Canadá foram descritas taxas de $37,8 \%$ e $59,5 \%$ de animais e de rebanhos, respectivamente, infectados pelo BHV-1 e programas imunoprofiláticos são de uso rotineiro neste país (DURHAM; HASSARD, 1990).

No Brasil, dados regionais, obtidos a partir de levantamentos sorológicos, revelam a expressiva disseminação do vírus em rebanhos de corte e leite. Mueller et al. (1981) encontraram $42,2 \%$ de animais reagentes no Estado de São Paulo. No Rio Grande do Sul foram descritas taxas de soropositividade de 81,7\% (RAVAZZOLO et al., 1989) e 71,3 \% (VIDOR et al., 1995).

Em um amplo estudo da freqüência de ocorrência de IBR no Brasil a presença de anticorpos anti-BHV-1 foi pesquisada em 21.062 amostras de soros de fêmeas bovinas de 1.992 rebanhos não vacinados contra IBR e com histórico de problemas reprodutivos. As amostras, colhidas no período de janeiro de 1997 a dezembro de 1998 em 21 estados brasileiros, foram analisadas pelo teste de ELISA (HerdCheckâ, Idexx Laboratories, EUA). Em 13.541 (64,3\%) amostras analisadas foram identificados anticorpos anti-BHV-1. Animais soropositivos foram encontrados em 1.886 (94,7\%) rebanhos e em todos os 21 estados da federação incluídos no estudo (RICHTZENHAIN et al., 1999).

No Estado do Paraná, Médici et al. (2000), também trabalhando em rebanhos com problemas reprodutivos, relataram que $41,9 \%$ das amostras de soro e $90,5 \%$ dos rebanhos de aptidão leiteira avaliados foram positivos para o BHV-1. Em rebanhos de corte, a freqüência de animais soropositivos e de rebanhos infectados foi de $50,8 \%$ e $100 \%$, respectivamente.

No Laboratório de Virologia Animal da Universidade Estadual de Londrina, no período de 1995 a 2001, testes sorológicos (ELISA e soroneutralização) para o diagnóstico da infecção pelo BHV-1 foram realizados em 26.441 amostras de soros sangüíneos de rebanhos bovinos de corte e de leite não vacinados contra IBR e com histórico de problemas reprodutivos. As amostras foram provenientes dos Estados do Paraná, São Paulo, Mato Grosso do Sul, Mato Grosso, Goiás e Rondônia. A Tabela 1 apresenta a freqüência de ocorrência de animais soropositivos distribuída por Estado da Federação (ALFIERI, dados não publicados).
Tabela 1 - Freqüência de ocorrência de diagnóstico sorológico do BHV-1 em bovinos adultos não vacinados contra a IBR e com histórico de problemas reprodutivos, Brasil, 1995-2001.

\section{Diagnóstico}

A diversidade dos sinais clínicos, bem como a presença dos mesmos sinais em outras doenças infecciosas e parasitárias, não permite a elaboração de um diagnóstico clínico conclusivo da infecção ocasionada pelo BHV-1. Até mesmo nos casos de vulvovaginite, onde as lesões são características, o diagnóstico é apenas presuntivo. Nesta forma de apresentação clínica é necessário, em particular, realizar o diagnóstico diferencial das infecções ocasionadas por Micoplasma bovigenitalium e Ureaplasma diversum que são responsáveis por vulvo-vaginite granular (RUHNKE et al., 1984).

Nos quadros clínicos que envolvem o sistema respiratório é importante diferenciar a infecção pelo BHV-1 daquelas ocasionadas por outros patógenos que estão agrupados no Complexo Respiratório Bovino, como o vírus respiratório sincicial bovino (BRSV), vírus da diarréia viral bovina (BVDV), vírus parainfluenza tipo 3 (PI-3) e bactérias do gênero Pasteurella (OBANDO et al., 1999).

Nos casos de encefalites (BHV-5), devem ser descartadas outras infecções e/ou patologias que comprometem o sistema nervoso central de bovinos como o vírus da raiva, babesiose cerebral, enterotoxemia, toxinfecções, intoxicação por plantas tóxicas, uréia, chumbo, acidentes ofídicos e encefalopatia espongiforme bovina (SANCHES et al., 2000).

Nos distúrbios reprodutivos ocasionados pelo BHV1 o diagnóstico clínico é praticamente impossível. 0 aborto, considerado a manifestação clínica mais evidente da infecção deve ainda ser diferenciado de outras causas infecciosas como a brucelose, leptospirose, campilobacteriose, neosporose, tricomonose e de infecções ocasionadas pelo vírus da diarréia viral bovina e por micoplasmas. Causas não infecciosas relacionadas ao manejo (estresse térmico), endotoxinas, corticosteróides exógenos, desordens genéticas e/ou nutricionais, teratogenia, plantas tóxicas, micotoxinas (zearalenona), entre outras causas, também devem ser incluídas no diagnóstico diferencial (LARSON, 1996).

O histórico sanitário do rebanho, relacionado com as taxas de produtividade, programas de vacinação e 
manejo alimentar, pode ter fundamental importância na elaboração do diagnóstico. Porém, somente com o apoio de técnicas laboratoriais o diagnóstico do BHV-1 é conclusivo.

O diagnóstico laboratorial da infecção pelo BHV-1 pode ser etiológico ou sorológico. Atualmente as técnicas sorológicas mais utilizadas na detecção de anticorpos específicos incluem a soroneutralização (SN) e os ensaios imunoenzimáticos (ELISA). Para minimizar o risco da introdução de animais infectados em rebanhos ou em centrais de inseminação, livres do BHV-1, os testes sorológicos devem ser sensíveis o suficiente para evitar resultados falso-negativos, principalmente quando os títulos de anticorpos específicos para o vírus são baixos. A detecção de animais portadores do vírus em latência também é de extrema importância nos programas de controle e erradicação da doença e, em algumas situações, essa identificação não é possível de ser realizada por meio de métodos sorológicos tradicionais uma vez que os animais podem apresentar baixo título de anticorpos para o BHV-1.

A técnica de soroneutralização (SN), pela dependência da manutenção de linhagens celulares, é onerosa. Devido a menor sensibilidade com relação à técnica de ELISA a SN pode ainda não detectar anticorpos em alguns animais que apresentem a infecção viral em estado de latência prolongada ou naqueles recentemente infectados. Nestas duas situações os animais podem apresentar títulos basais de anticorpos neutralizantes que não são detectáveis por meio deste procedimento sorológico, originando com isto resultados falso-negativos (WYLER et al., 1989).

Kramps et al. (1994) demonstraram que o teste de ELISA, empregado na detecção de anticorpos neutralizantes da glicoproteína gB do BHV-1, foi mais sensível que a técnica de soroneutralização, tendo sido capaz de detectar baixo título de anticorpos em animais inoculados experimentalmente.

Em trabalhos posteriores, devido às divergências nos resultados entre os testes de soroneutralização, ELISA e de imunofluorescência indireta, Kramps et al. (1996), demonstraram a necessidade de uma padronização efetiva dos testes sorológicos para a identificação de animais com títulos limiares de anticorpos para o BHV-1.

Entretanto, as técnicas de soroneutralização e ELISA podem ser inviabilizadas como recurso diagnóstico em rebanhos que adotam a vacinação profilática. Embora sejam importantes na identificação de animais que foram expostos ao vírus, e conseqüentemente apresentam conversão sorológica, estas metodologias são incapazes de diferenciar os títulos provenientes da exposição ao vírus vacinal daqueles oriundos da exposição natural ao vírus de campo.

Desta forma, o diagnóstico da infecção pelo BHV-1 somente é conclusivo mediante a elaboração de metodologias que possibilitem o diagnóstico etiológico. Para isto podem ser utilizadas técnicas que identifiquem: i) a partícula viral, como o isolamento do vírus em cultivo celular e a microscopia eletrônica; ii) os antígenos virais, por meio de técnicas como imunofluorescência, imunoperoxidase e ELISA diretos; iii) o genoma viral, por técnicas moleculares como a hibridização e a reação em cadeia pela polimerase (WYLER et al., 1989).

O isolamento do BHV-1 em cultivo celular é considerado o método de diagnóstico etiológico padrão. Entretanto, é uma técnica laboriosa, de custo elevado e dispendiosa em relação ao tempo dedicado para a sua elaboração. Esta metodologia apresenta ainda como desvantagem a necessidade de material clínico bem conservado, já que a técnica exige a presença de partículas virais viáveis, ou seja, infectantes. Nos abortos comprovadamente ocasionados pelo BHV-1 em somente $40 \%$ dos casos foi possível o isolamento viral. Isto ocorre principalmente devido às oscilações de temperatura, as quais o vírus é lábil, inviabilizando o isolamento pela perda da infecciosidade da partícula viral (KIRKBRIDE, 1992). O tempo exigido para a obtenção de resultados é outra desvantagem da técnica pois são necessários, no mínimo, de 14 a 28 dias para a conclusão do diagnóstico.

O atraso no trânsito das amostras biológicas do campo até o laboratório, associado às más condições de estocagem do material, são condições incompatíveis com esse procedimento diagnóstico, uma vez que as partículas virais devem permanecer viáveis e, conseqüentemente, infectivas. Alguns tecidos contêm ainda enzimas que são tóxicas para o cultivo de células e, adicionalmente, podem conter inibidores que interferem no processo de isolamento viral (EDWARDS et al., 1983).

O isolamento do BHV-1 a partir de amostra de sêmen também pode ser de difícil realização devido, principalmente, à toxicidade natural do plasma seminal sobre a monocamada celular (KAHRS, 1977; SCHULTZ et al., 1982).

As técnicas de imunoperoxidase e imunofluorescência, apesar de não exigirem a infecciosidade da partícula viral, também podem ser seriamente comprometidas pelas más condições de transporte e estocagem citadas anteriormente. Isto ocorre porque tais metodologias, para o sucesso do diagnóstico, exigem fundamentalmente a integridade estrutural da partícula e das proteínas virais. Outro fator limitante é o método de preparo do esfregaço celular que exige um número de células adequado para a leitura das lâminas e também a disponibilidade de um anti-soro detector de boa qualidade.

A técnica de imunofluorescência requer um grande número de células infectadas pelo vírus e um técnico experiente para realizar a leitura das lâminas, incluindo também a boa qualidade dos reagentes que não são facilmente disponíveis. Reações inespecíficas podem ocorrer em tecidos autolisados ou em tecidos com contaminação bacteriana secundária. Edwards et al. (1983) verificaram que a leitura das lâminas teve um resultado satisfatório e de confiabilidade por um prazo máximo de três dias de estocagem do material. Após esse período houve uma progressiva destruição da 
arquitetura celular e redução acentuada no número de células íntegras no esfregaço.

Outro método de diagnóstico direto é o teste de ELISA. Collins et al. (1988) desenvolveram um sistema de ELISA de captura de antígeno para a detecção do BHV-1 utilizando swabs nasais de animais infectados. Apesar da alta especificidade, o teste revelou ser pouco sensível, incapaz de detectar títulos virais inferiores a $1 \times 10^{5} \mathrm{TCID}_{50}$.

Diante destes inconvenientes e da necessidade do desenvolvimento de um método de diagnóstico mais específico, sensível e rápido foram desenvolvidas técnicas moleculares para a detecção do genoma do BHV-1 diretamente em amostras clínicas. Inicialmente foram empregadas as técnicas de hibridização, que consistem basicamente em detectar seqüências alvo do DNA viral por meio de sondas (probes) ligadas a marcadores. Embora seja um método altamente específico, a hibridização também pode falhar na detecção de animais com baixo título viral, como ocorre nos casos de infecção latente (BELÁK; BALLAGI-PORDÁNY, 1993; VILCEK et al., 1994).

Com isto, uma técnica de amplificação, a reação em cadeia pela polimerase (PCR) está sendo muito utilizada como método diagnóstico, cujo princípio baseiase fundamentalmente na simulação e repetição seriada de processos celulares in vitro, para a síntese exponencial de seqüências de DNA (Mc PHERSON et al., 1994).

Entre as vantagens da técnica de PCR está incluída a ampla variedade de amostras biológicas que podem ser utilizadas no diagnóstico, tais como: fragmentos de tecidos de feto abortado, sistema nervoso central, secreções, sêmen e cultura de tecidos, contendo partículas virais viáveis e não viáveis. $A$ técnica de PCR possibilita a detecção de partículas virais não infectantes, pois a análise é feita por meio da identificação do genoma viral (HAYDEN et al., 1991; BÉLAK; BALLAGIPORDÁNY, 1993).

Portanto, o impacto causado pelo atraso no trânsito das amostras até o laboratório e pela condição inapropriada de transporte e/ou estocagem é consideravelmente inferior quando comparado aos demais métodos de diagnóstico direto citados anteriormente. Além disso, resultados conclusivos podem ser obtidos em poucas horas, revelando também ser um método altamente sensível e específico (ERLICH et al., 1991).

O emprego da técnica de PCR também tem contribuído para elucidar a patogenia da infecção pelo BHV1. Mweene et al. (1996) identificaram os sítios de latência do vírus em animais experimentalmente infectados, sendo o DNA isolado e amplificado a partir do gânglio trigêmio, ovário, pulmão, mucosas nasal e traqueal, baço, nódulos linfáticos pré-escapular e pré-crural e de leucócitos.

Como o BHV-1 é eliminado de forma intermitente no fluido seminal a técnica de PCR também pode ser empregada efetivamente como um método de monitoramento e de controle da qualidade do sêmen de bovinos soropositivos e, conseqüentemente, portadores do vírus. Esse procedimento permite a manutenção, em regime de colheita de sêmen, de animais de alto valor zootécnico soropositivos para o BHV-1 e, principalmente, minimiza os riscos de transmissão da doença em centrais de coleta de sêmen (GEE et al., 1996).

A eficácia da PCR na detecção do BHV-1 em amostras clínicas, naturalmente ou artificialmente infectadas, tem sido descrita. Com freqüência são realizadas amplificações de regiões conservadas dos genes que codificam: i) a glicoproteína B (VILCEK et al., 1994; MASRI et al., 1996; MWEENE et al., 1996; SANTURDE et al., 1996; KATARIA et al., 1997; ROCHA et al., 1998); ii) a glicoproteína C (VAN ENGELENBURG et al., 1993; KATARIA et al., 1997); iii) a glicoproteína D (WEIDMANN et al., 1993; GEE et al., 1996; WAGTER et al., 1996; ZHOU et al., 1999); e iv) a timidina kinase (KIBENGE et al., 1994; YASON et al., 1995; MOORE et al., 2000).

Trabalhos comparativos com outras metodologias de diagnóstico comprovam a eficiência da PCR na identificação de animais infectados pelo BHV-1. Xia et al. (1995), demonstraram que a PCR, associada à técnica de Southern Blot, foi 100 vezes mais sensível do que o isolamento viral em cultivo celular. Resultados semeIhantes foram obtidos por Van Engelenburg et al. (1995) que identificaram o BHV-1 no sêmen por um maior período de tempo após a infecção ou a reativação do vírus.

A técnica de PCR também foi capaz de detectar o BHV-1 precocemente, a partir do quarto dia pós-infecção, antes mesmo do aparecimento de anticorpos detectáveis pelos procedimentos sorológicos tradicionais (MASRI et al., 1996).

Outra importante vantagem relacionada à técnica de PCR é a possibilidade da identificação dos subtipos virais que pode ser obtida pela: i) análise do perfil de restrição do produto amplificado após a digestão com enzimas de restrição; ii) Southern blotting utilizando sondas (probes) específicas; e iii) seqüenciamento genômico (MILLER et al., 1988; d'OFFAY et al., 1993; XIA et al., 1995). A caracterização dos sub-tipos virais circulantes em uma região e/ou período pode contribuir significativamente com estudos de caráter epidemiológico, antigênico e molecular do BHV-1. Estes estudos apresentam grande impacto nas condutas de diagnóstico, controle e profilaxia desta importante virose dos bovinos.

\section{Referências}

ACKERMANN, M.; PETERHANS, E.; WYLER, R. DNA of Bovine Herpesvirus type 1 in the trigeminal ganglia of latently infected calves. Am. J. Vet. Res, v.43, n.1, p.36-40, 1982.

ACKERMANN, M.; WYLER, R. The DNA of an IPV strain of bovide herpesvirus 1 in sacral ganglia during latency after intravaginal infection. Vet. Microbiol., v.9, p.53-63, 1984.

ACKERMANN, M. et al. Round table on infectious bovine rhinotracheitis/infectious pustular vulvovaginitis virus infection diagnosis and control. Vet. Microbiol., v.23, p.361363, 1990. 
BÉLAK, S.; BALLAGI-PORDÁNY, A. Application of the polymerase chain reaction (PCR) in veterinary diagnostic virology. Vet. Res. Comm., v.17, p.55-72, 1993.

COLLINS, J.K.; AYERS, V.K.; CARMAN, J. Evaluation of an antigen-capture ELISA for the detection of bovine herpesvirus type 1 shedding from feedlot cattle. Vet. Microbiol., v.16. p.101-107, 1988.

DENNETT, D.P.; BARASA, J.O.; JOHNSON, R.H. Infectious bovine rhinotracheitis virus: studies on the venereal carrier status in range cattle. Res. Vet. Sci., v.20, p.77-83, 1976.

d'OFFAY, J.M.; MOCK, R.E.; FULTON, R.W. Isolation and characterization of encephalitic bovine herpesvirus type 1 isolates from cattle in North America. Am. J. Vet. Res., v.54, n.4, p.534-539, 1993.

DURHAM, P.J.K.; HASSARD, L.E. Prevalence of antibody to infectious bovine rhinotracheitis, parainfluenza 3 , bovine respiratory syncytial, and bovine viral diarrhea viruses in cattle in Saskatchewan and Alberta. Can. Vet. J., v.31, p.815820, 1990.

EAGLESOME, M.D.; GARCIA, M.M. Microbial agents associated with bovine genital tract infectious and semen. Part I. Brucella abortus, Leptospira, Campylobacter and Trichomonas foetus. Vet. Bull., v.62, n.8, p.743-775, 1992.

EDWARDS, S.; CHASEY, D.; WHITE, H. Experimental infectious bovine rhinotracheitis: comparison of four antigen detection methods. Res. Vet. Sci., v.34, p.42-45, 1983.

ELAZHARY, M.A.S.Y. et al. Bovine herpesvirus type 1 in the sperm of a bull from a herd with fertility problems. Can. Vet. J., v.21, p.336-339, 1980.

ENGELS, M.; ACKERMANN, M. Pathogenesis of ruminant herpesviruses infections. Vet. Microbiol., v.53, p.3-15, 1996.

ERLICH, H. A.; GELFAND, D.; SNINSKY, J.J. Recents Advances in the polymerase chain reaction. Science, v.252, p.1643-1651, 1991.

FEHLER, F. et al. Glycoprotein IV of bovine herpesvirus 1 expressing cell line complements and rescues a conditionally lethal viral mutant. J. Virol., v.66, n.2, p.831839, 1992.

FENNER, F. Veterinary Virology. $1^{\text {st }}$ ed. Londres: Academic Press, 1987. $445 \mathrm{p}$.

GEE, A.L.W.; WAGTER, L.H.A.; HAGE, J.J. The use of polymerase chain reaction assay for the detection of bovine herpesvirus 1 in semen during a natural outbreak of infectious bovine rhinotracheitis. Vet. Microbiol., v.53, p.163168,1996

GIBBS, E.P.J.; RWEYEMANN, M.M. Bovine herpesviruses. Part I. Bovine herpesvirus 1. Vet. Bull., v.47, n.5, 1977.

HAYDEN, J.D. et al. The promises and pitfalls of PCR. Reviews in Medical Microbilogy, v.22, p.129-137, 1991.

KAHRS, R.F. Infectious Bovine Rhinotracheitis: A review and update. J. Am. Vet. Méd. Assoc., v.171, n.10, p.10551064, 1977.

KATARIA, R.S. et al. Detection of bovine herpesvirus 1 (BHV1) genomic sequences in bovine semen inoculated with BHV-1 by polymerase chain reaction. Acta Virol., v.41, p.311315, 1997.

KIBENGE, F.S.B. et al. Amplification of strains of bovine herpesvirus 1 by use of polymerase chain reaction with primers in the thymidine kinase region. Am. J. Vet. Res., v.55, n.9, p.1206-1212, 1994.

KIRKBRIDE, C.A. Manangin and outbreak of liverstock abortion 2: diagnosis and control of bovine abortion. Vet. Med., v.80, n.5, p.70-79, 1985.

KIRKBRIDE, C.A. Etiologic agents in a 10 year study of bovine abortions and stillbirths. J. Vet. Diagn. Invest., v.4, n.2, p.160-175, 1992.

KRAMPS, J.A. et al. A simple, specific, and highly sensitive blocking enzyme-linked immunosorbent assay for detection of antibodies to bovine herpesvirus 1. J. Clin. Microbiol., v.32, n.9, p.2175-2181, 1994.

KRAMPS, J.A. et al. A European inter-laboratory trial to evaluate the reliability of serological diagnosis of bovine herpesvirus 1 infectious. Vet. Microbiol., v.53, p.153-161, 1996.

LARSON B.L. Diagnosing the cause of bovine abortions and other perinatal deaths. Vet. Med., v.81, p.478-486, 1996.

MASRI, S.A. et al. Rapid detection of bovine herpesvirus 1 in the semen of infected bulls by a nested polymerase chain reaction assay. Can. J. Vet. Res., v.60, p.100-107, 1996.

McPHERSON, Q.P.; TAYLOR, G.R.; QUIRKE, P. PCR a practical approach. Oxford: Information Press, Ltd.,1994. $247 \mathrm{p}$.

MÉDICI, K.C.; ALFIERI, A.F.; ALFIERI, A.A. Prevalência de anticorpos neutralizantes contra o herpesvírus bovino tipo 1 , decorrente de infecção natural, em rebanhos com distúrbios reprodutivos. Ciência Rural, v.30, n.2, p.347-350, 2000.

MILLER, J.M.; VAN DER MAATEN, M.J.; WHETSTONE, C.A. Effects of a bovine herpesvirus-1 isolate on reproductive function in heifers: Classification as a type-2 (infectious pustular vulvovaginitis) virus by restriction endonuclease analysis of viral DNA. Am. J. Vet. Res., v.49, n.10, 1988.

MOORE, S.; GUNN, M.; WALLS, D. A rapid and sensitive PCR-based diagnostic assay to detect bovine herpesvirus 1 in routine diagnostic submissions. Vet. Microbiol., v.75, p.145-153, 2000.

MUELLER, S.B.K. et al. Prevalência de anticorpos contra o vírus da Rinotraqueíte Infecciosa Bovina / Vulvovaginite Pustular Infecciosa (IBR/IPV) em bovinos do Estado de São Paulo. Instituto Biológico de São Paulo, v.47, n.2, p.5559, 1981.

MWEENE, A.S.; OKAZAKI, K.; KIDA, H. Detection of viral genome in non-neural tissues of cattle experimentally infected with bovine herpesvirus 1. Jpn. J. Vet. Res., v.44, n.3, p.165-174, 1996.

OBANDO, C. et al. Serological and molecular diagnosis of bovine viral diarrhoea virus and evidence of other viral infections in dairy calves with respiratory disease in Venezuela. Acta Vet. Scan., v.40, n.3, p.253-262, 1999.

OKAZAKI, K. et al. Bovine herpesvirus 1 gp 87 mediates both attachment of virions to susceptible cells and haemaglutination. Arch. Virol., v.97, p.297-307, 1987.

PAULI, B. et al. IBR/IPV viruses: genome structure and diseases. Med. Microbiol. Immunol., v.169, p.129, 1981.

PHILPOTT, M. The dangers of disease transmission by artificial insemination and embryo transfer. Br. Vet. J., v.149, n.4, p.339-369, 1993. 
RAVAZZOLO, A.P.; PIZZOL, M.D.; MOOJEN, V. Evidência da presença de anticorpos para o vírus da Rinotraqueíte Infecciosa dos Bovinos, em alguns municípios do Estado do Rio Grande do Sul, Brasil. Arq. Fac. Vet. UFRGS, v.17, p.89-95, 1989.

RICHTZENHAIN, J.J. et al. Pesquisa de anticorpos séricos contra o herpesvírus bovino tipo 1 (BHV-1) em fêmeas bovinas de propriedades com histórico de problemas reprodutivos localizadas em 21 estados brasileiros. Arq. Inst. Biol., v.66 (supl), p.127, 1999.

ROCHA, M.A. et al. A high sensitivity-nested PCR assay for BHV-1 detection in semen of naturally infected bulls. Vet. Microbiol., v.63, p.1-11, 1998.

ROEHE, P.M. et al. Diferenciação entre o vírus da Rinotraqueíte Infecciosa bovina (BHV-1) e herpesvírus da encefalite bovina (BHV-5) com anticorpos monoclonais. Pesq. Vet. Bras., v.17, n.1, p.41-44, 1997.

RUHNKE, H.L. et al. Bovine abortion and neonatal death associated with Ureaplasma diversum. Theriogenology, v.21, p.295-301, 1984.

SANCHES, A.W.D. et al. Doenças do sistema nervoso central em bovinos no Sul do Brasil. Pesq. Vet. Bras. v.20, n.3, p.113-118, 2000.

SANTURDE, G. et al. Rapid and high sensitivity test for direct detection of bovine herpesvirus-1 genome in clinical samples. Vet. Microbiol., v.49, p.81-92, 1996.

SCHULTZ, R.D. et al. A method to test large numbers of bovine semen samples for viral contamination and results of a study using this method. Theriogenology, v.17, p.115123, 1982

SCHWYZER, M.; ACKERMANN, M. Molecular Virology of ruminant herpesviruses. Vet. Microbiol., v.53, p.17-29, 1996.

STRAUB, O.C. Infectious bovine rhinotracheitis vírus. In: DINTER, Z.; MORUN, B. Virus Infectious of Ruminants. Amsterdam: Elsevier Science Publishers, 1990, p.71-108.

STRAUB, O.C. BHV-1 Infectious: Relevance and spread in Europe. Comp. Immunol. Microbiol. Infect. Dis., v.14, n.2, p.175-186, 1991.

VAN DONKERSGOED, J.; BABIUK, L.A. Diagnosing and managing the respiratory form of infectious bovine rhinotracheitis. Vet. Med., v.86, n.1, p.86-94, 1991.
VAN DRUNEN LITTEL - VAN DER HURK, S.; HUGUES, G.; BABIUK, L.A. The role of carbohydrate in the antigenic and immunogenic structure of bovine herpesvirus type 1 glycoproteins gl and gIV. J. Gen. Virol., v.71, p.2053-2063, 1990.

VAN ENGELENBURG, F.A.C. et al. Development of a rapid and sensitive polymerase chain reaction assay for detection of bovine herpesvirus type 1 in bovine semen. J. Clin. Microbiol.. v.31, n.12, p.3129-3135, 1993.

VAN ENGELENBURG, F.A.C. et al. Excretion of bovine herpesvirus 1 in semen is detected much longer by PCR than virus isolation. J. Clin. Microbiol., v.33, n.2, p.308-312, 1995.

VIDOR, T. et al. Herpes bovino tipo 1 (BHV-1): I. Sorologia de rebanhos com problemas reprodutivos. Ciência Rural, v.25, n.3. p.421-424, 1995.

VILCEK, S. et al. Rapid detection of bovine herpesvirus 1 (BHV 1) using the polymerase chain reaction. Vet. Microbiol., v.42, p.53-64, 1994.

WAGTER, L H.A. et al. A polymerase chain reaction (PCR) assay for the detection of bovine herpesvirus 1 (BHV1) in selectively digested whole bovine semen. Vet. Res. Comm., v.20, p.401-408, 1996.

WEIDMANN, M. et al. Detection of bovine herpesvirus-1 in bovine semen by a nested PCR assay. J. Virol. Meth. v.44, p.129-140, 1993.

WYLER, R.; ENGELS, M.; SCHWYZR, M. Infectious bovine rhinotracheitis/vulvovaginitis (BHV-1). In: WITTMANN, G. Herpesvirus diseases of cattle, horses and pigs. Boston: Kluwer Academic Publishers, 1989. p.1-72.

$X I A, J . Q$. et al. Detection of bovine herpesvirus 1 in the semen of experimentally infected bulls by dot-blot hybridisation, polymerase chain reaction and virus isolation. Res. Vet. Sci., v.59, p.183-185, 1995.

YASON, C.V. et al. Establishment of conditions for the detection of bovine herpesvirus-1 by polymerase chain reaction using primers in the thymidine kinase region. Can. J. Vet. Res., v.59, p.94-101, 1995.

ZHOU, J. et al. Improved detection of bovine herpesvirus 1 in artificially infected bovine semen by protein amplification. J. Virol. Meth., v.79, p.181-189, 1999. 
